\title{
On Predication, Derivation and Anti-Locality
}

This paper pursues the question what the implications of the Anti-Locality Hypothesis could be for the syntax of secondary predication. Focus of the discussion will be an investigation of what their internal structure of small clause complements must look like, how these small clause complements connect to their matrix environments, and what the relevance could be for the formulation of anti-locality presented here. Anti-locality is defined over a tripartite clause structure (split into three Prolific Domains) and a PF-condition on the computation (the Condition on Domain-Exclusivity). The investigation revolves around two leading questions: (i) does the syntax of small clauses involve more structure than simply [sc DP XP] and (ii) do small clauses constitute their own Prolific Domain (or maybe even more)? The results, affirmative answers to both questions, are also relevant for other types of secondary predication.

\section{Introduction}

This paper explores the relevance to selected issues of secondary predication of the framework presented in my dissertation work (Grohmann 2000a), which concerns a lower bound on locality - the distance between two positions in a given (movement) dependency - formulated in terms of anti-locality. It concentrates on a treatment of small clause-complements in this framework.

In the first part of the paper, I present the Anti-Locality Hypothesis, discussing a clausal tripartition into Prolific Domains, how these connect to clause structure, and what kind of assumptions about the computational system this anti-locality framework assumes (section 2). The major theoretical proposal is the Condition on Domain Exclusivity, which bans movement of a maximal phrase within a Prolific Domain and the introduction of Copy Spell Out, a principled mechanism to ensure Exclusivity, even in apparently illegitimate structures (section 3). This part introduces the basic sets of data supporting the Anti-Locality Hypothesis and the framework laid out. It also sets the stage for the second part of the paper by turning to ECM-constructions.

\footnotetext{
This paper grew out of preparations for "Derivation and Predication in an Anti-Locality Framework," a talk which I was supposed to present at the Workshop on Syntax of Predication at ZAS in Berlin (November 2-3, 2001). Unfortunately, I became ill right before the workshop, and all of the talk that survived is a hand-out. I am grateful to Niina Zhang, the organizer of the workshop, for all her help before and during the workshop, and for distributing the hand-out. As I wasn't present at the actual workshop, I cannot thank anyone for feedback and thus take full responsibility for everything let out in these pages. I am grateful, however, to Juan Carlos Castillo, John Drury and Joachim Sabel for discussing some of the material.
} 
The second part investigates the relevance of this framework for secondary predication, focusing on the syntax of a class of constructions subsumed under the term "small clause" (SC). Based on the discussion of how reflexive subjects of ECM-complements be best treated in an anti-locality framework, we will face the puzzle extended to SC-complements (section 4). An intermezzo introduces the complex issues of the format of SCs (or better, SC-complements) in the current framework (section 5). Our discussion of these as well as other cases of secondary predication will lead us to the conclusion that the syntax of ECM- and SC-complements isn't too different after all (section 6). Then a discussion follows of the structure of SCs, as relevant to the anti-locality framework (section 7). A conclusion wraps up this paper (section 8).

\section{Anti-Locality and Prolific Domains}

One robust result of generative research on movement dependencies (or construal) is that they are bounded; a dependency is subject to (often, strict) locality conditions. Locality is typically understood as an upper bound on distance. ${ }^{1}$ (1) illustrates how locality restricts the formation of selected dependencies, relevant for the ensuing discussion. Assuming the Copy Theory of movement (Chomsky 1995, Nunes 1995), lower occurrences of moved elements are crossed out.

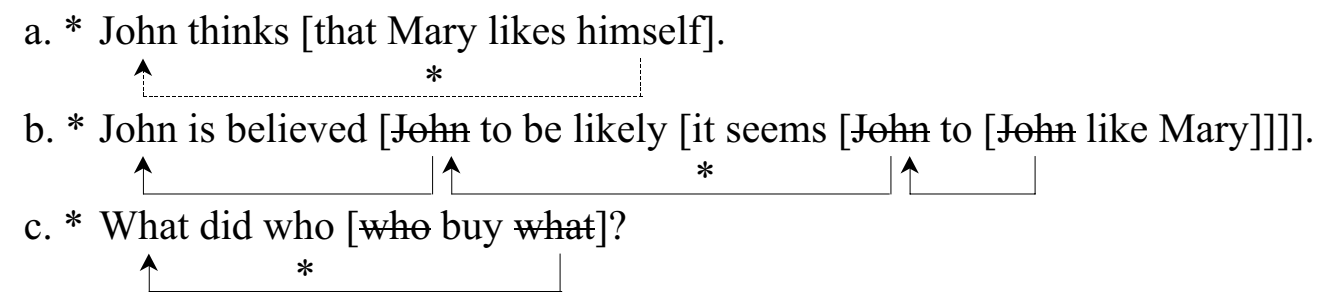

In (1a) the dependency between the reflexive himself and the attempted antecedent John cannot be established: ${ }^{2}$ for whatever reason (commonly formulated in terms of Binding Theory), the intervening DP Mary blocks this dependency formation (indicated by the star) — or, in other terms, the distance between the two elements is too far, subject to locality. The movement dependency between the highest and lowest occurrence of John in (1b) is also illicit: the second most deeply embedded copy of John (traditionally, the result of movement from the thematic agent to the canonical subject position) cannot move across $i t$ and thus skip a potential landing

I concentrate on "anti-locality" effects and a formal way to capture these, rather than on standard locality effects or definitions. This connection is discussed explicitly in Grohmann (2001b). It thus suffices to say that by and large locality can be characterized by Relativized Minimality (Rizzi 1990), integrated into the minimalist framework in a variety of ways, all involving some notion of "distance" — "Shortest Move," "Minimal Link," "Fewest Steps" etc. (see Chomsky 1995, Zwart 1996, Nunes 1999, Hornstein 2001a, and many others for discussion). Concerning the usage of "dependency," I take a strictly derivational approach to the computational system, as will become clear presently, and leave aside how a more (or even strict) representational view could be integrated (viz. chain formation, for example), at least for purposes of exposition.

2 In standard approaches, reflexives are subject to Condition A, i.e. a result of binding a fully lexical pronominal element. Most approaches don't assume a movement analysis of binding relations. I indicate this by the broken line, as opposed to full lines (arrows) indicating movement. We will soon modify this view of local reflexives and introduce a movement analysis, much in spirit of recent approaches, but for slightly different reasons. 
site. Again, the violating step is marked by ' $*$ ' and ruled out by standard locality conditions (see fn.1). (1c), finally, illustrates an ill-formed dependency concerning movement to Comp. One way of capturing the illicit movement in this case is to say that another relevant element, i.e. one of the same "type" (in this case, one also bearing a Wh-feature), is closer to the landing site than what, which cannot skip over this intervening element (here, who).

This very rough sketch of how locality conditions may restrict dependency formation is nothing new, hence can be left sketchy as is. One question that has not yet been asked is whether there is the opposite restriction to (the locality of) dependency formation too. We could thus ask whether there is also a lower bound on distance, banning movement that is too close. I argue that such a restriction does indeed exist. As it seems to be the opposite restriction of what standard locality conditions cover, I call it "anti-locality."

The examples in (2)-(4) illustrate what anti-locality could capture, if formulated properly (where, as throughout, '*' marks linguistic ungrammaticality and '\#' an ill-formed derivation).

(2) a. * John likes.

b. \# [vp John $v$ [vp likes John] $]$

(3) a. * Him likes she/her.

b. \# [те him T [AgrOP him AgrO [ ${ }_{\mathrm{vP}}$ him $v$ [vP likes she/her]]]]

(4) a. * Who, John saw? / Who, did John see? / Who did, John see?

b. \# [TорP who Top [Focp whø (did-)Foc [тр John saw/see ... (whø) ...]]]

We could thus ask why one thematically marked element may not move to another thetaposition, as in (2). One could envision an interpretation of identity, as in John likes himself, for example. Likewise, DPs don't seem to receive two structural cases, but Case-checking is restricted to on(c)e per DP. In other words, movement from one Case-position (say, AgrOP), checking accusative, to another, picking up nominative, as suggested in (3b), is illicit. (Note that one could assign Case to the argument left behind through some default strategy, or other means, but neither she nor her would be grammatical in this scenario.) Lastly, movement of a wh-phrase to some other position within the Comp-layer seems to be ruled out as well. The ungrammaticality of either version depicted in (4a) could follow from too close a movement, as shown in (4b): movement to a Wh-checking position (such as FocP, as Rizzi 1997, among others, argues for) cannot be followed by topicalization. (Leaving aside details regarding the role of $d o$-insertion, as indicated by the three options in (4a).)

Let's sum up what these data and hypothetical derivations show us. The structures in the bexamples share one property: all indicated movement steps involve two closely related positions. In $(2 b)$ there is movement from one theta- to another theta-position. (3b) suggests movement from one agreement-related or phi-position to another phi-position. And the hypothetical derivation (4b) involves movement from one Comp- to another Comp-position. (Contrast these "closely related" positions with the type of positions related in (1a), (1b) and (1c), respectively.)

Under traditional approaches, both within GB theory as well as most minimalist versions, these derivational steps are easily ruled out. The movement in (2b) violates the Theta Criterion. The Case Filter accounts for the illicitness of moving from one phi- to another phi-position and check two different Case features, as in (3). Various "Affect Criteria" (such as the Wh-Criterion) could account for the ungrammaticality of (4a), or the ill-formed derivation (4b). 
Scrutinizing core minimalist premises, however, this line isn't tenable anymore, or should at least be seriously rethought. One clear desideratum of any minimalist approach to linguistic theory is that all conditions on the computation must follow from Bare Output Conditions, namely those that relate directly to the conceptual-intentional and articulatory-perceptual interfaces (Chomsky 1995: 221ff.). With the elimination of D- and S-structure as "levels of representation," PF and LF are the sole interface levels (or, less representationally, components). As such, all D-structure remnants in the theory should be dispensed with. The only way to make sense of this desideratum is to derive all filters, principles and conditions on the computation from Bare Output Conditions. One plausible candidate is certainly the principle of Full Interpretation, a condition of the conceptual-intentional interface imposed on LF (Hornstein 2001a: 15). Less plausible candidates are arguably the Theta Criterion, Case Filter or Affect Criteria, as these do not directly relate to the two interface systems. Rather than appealing to additional filters, principles or conditions, we would like to know now whether structures as depicted in (2)-(4) can be ruled out on independent grounds, or by one general condition.

I suggest that an explanation in terms of anti-locality offers a positive answer:

Anti-Locality Hypothesis

Movement must not be too local.

Given (2)-(4) above, the most straightforward way to capture "too local" movement could be movement within a specific part of the clause, or a "domain" of sorts, sketched in (6):

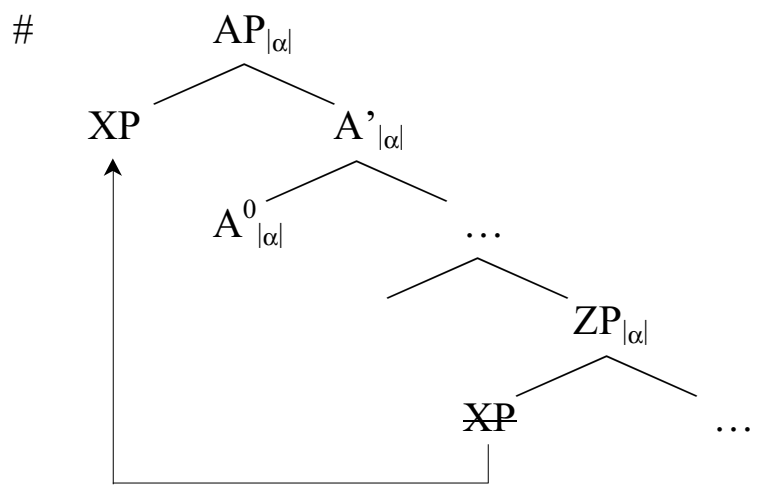

If a ban such as indicated in (6) is on the right track, we would need a means to compute the relevant domain within which movement of an XP, as illustrated in (2)-(4), is ruled out. Call this domain a Prolific Domain, characterized along the following lines. The part or domain relevant to compute "too local" or anti-local movement corresponds to a domain of shared contextual information - a Prolific Domain. As generalized in (6), a Prolific Domain may contain thematic context (a " $\theta$-domain"), agreement context (a " $\phi$-domain"), or discourse context (an " $\omega$-domain") — where $|\alpha|$ in (6) would thus correspond to one of $\{|\theta|,|\phi|,|\omega|\}$.

Let's define a Prolific Domain (abbreviated to $\Pi \Delta$ in structural representations) as follows:

\section{(7) Prolific Domain (П $\triangle$ )}

A Prolific Domain $\Pi \Delta$ is a contextually defined part of the computational system,

i. which provides the interfaces with the information relevant to the context and

ii. which consist of internal structure, interacting with derivational operations. 
Such a view offers a natural tripartition of the clause, where each part is locally licensed:

\section{Clausal Tripartition}

i. $\theta$-domain: The part of the derivation where theta relations are created.

ii. $\phi$-domain: The part of the derivation where agreement properties are licensed.

iii. $\omega$-domain: The part of the derivation where discourse information is established.

The "contextual domains" are thus Prolific Domains. They are prolific because each domain may is arguably made up of finer articulated structure; such as $v \mathrm{P}>\mathrm{VP}(\theta$-domain), or $\mathrm{TP}>$ AgrOP (and whatever else is needed in the $\phi$-domain), or TopP $>$ FocP (and more, such as $\mathrm{CP} /$ ForceP, for example, for the $\omega$-domain). They are domains in the usual sense, denoting a particular (and unique) part of the structure characterized by contextual information. ${ }^{3}$ Beyond mere terminology, the anti-locality framework sketched here offers a novel way of formalizing the intuitive tripartition of the clause (see fn. 3). This will be outlined in the next section.

\section{Exclusivity and Copy Spell Out}

If movement within a Prolific Domain is to be ruled out, as the data in (2)-(4) suggest, this ban should follow from Bare Output Conditions, or the argument to simplify our inventory of rules goes down the drain. Let's now focus on such a view of the anti-locality framework.

The one and only condition that I would like to propose, needed to account for all antilocality effects, is the Condition on Domain Exclusivity.

(9) Condition on Domain Exclusivity (CDE)

An object $\mathrm{O}$ in a phrase marker must have an exclusive Address Identification AI

per Prolific Domain $\Pi \Delta$, unless duplicity yields a drastic effect on the output.

i. $\quad \mathrm{An} \mathrm{AI}$ of $\mathrm{O}$ in a given $\Pi \Delta$ is an occurrence of $\mathrm{O}$ in that $\Pi \Delta$ at $\mathrm{LF}$.

ii. A drastic effect on the output is a different realization of $\mathrm{O}$ at $\mathrm{PF}$.

The main assumption is that LF and PF are accessed cyclically, in the sense of multiple applications of the operation Spell Out, proposed by Uriagereka (1999). (See also Chomsky 2000 and subsequent work, although in a different framework.) This would lead us to say that LF and $\mathrm{PF}$ are interface components, rather than levels of representation. AI is then taken to be "interpretive visibility": the LF-presence of an object in the phrase marker (from (9i)), coupled with a unique PF-matrix (per (9ii)). As a result, anti-locality is a PF-condition. As such it follows, as desired, straight away from Bare Output Conditions, viz. the CDE. The long and short of (9) is that an expression must have one and only one phonological occurrence in a given Prolific Domain, whether it is pronounced or not.

3 Note that this tripartition is nothing new or revolutionary, but rather reminiscent of earlier conceptions of the clause - cf. [ COMP [ INFL [ VP ]]] from Chomsky (1986a), for example. The proliferation of functional projections, from the works of, among many others, Pollock (1989), Chomsky (1991), Hale \& Keyser (1993), Baker (1997), Rizzi (1997), Poletto (2000), and the tripartition assumed in Platzack (2001) are also relevant in this context. What is new, however, is the formalized tripartition envisioned here (opposed to, say, Platzack's). 
Within Copy Theory we understand multiple occurrences of an object in the phrase marker to be non-distinct copies of that object. In other words, the CDE concerns XPs only: by definition head movement creates a new object (via adjunction), as morphemes (pronounced or not) - the "real" input of functional heads - obligatorily change the PF-matrix of the moved head. (See Grohmann 2000a: 58ff. for detailed discussion.)

This understanding of the computation makes one simple prediction. If a dependency between two positions within the same Prolific Domain were to involve different PF-matrices, the CDE should be satisfied. Following recent discussion in the literature, this prediction seems indeed to be borne out.

Let's discuss some ideas on implementing a strictly derivational view of the computational system. Taking certain pronouns as grammatical formatives, rather than fully lexical expressions (see among others Aoun \& Benmamoun 1998, Aoun, Choueiri \& Hornstein 2001, Hornstein 2001a for discussion), domain-internal dependencies with a different PF-matrix assigned to each copy can indeed be found: as grammatical formatives, these pronouns are thus derived.

One example concerns the relation between the peripheral XP and a coreferent resumptive pronoun (RP) in certain left dislocation constructions - but not others. There is a type of left dislocation that exhibits clear diagnostics for movement. (10) is one such instance, illustrating the availability of a bound variable reading between a quantified subject and a pronoun contained in the left-dislocated constituent (where the left-dislocated constituent and the RP are in an "antilocal relationship," as shown in (10b): CP and TopP are part of the $\omega$-domain). (The coreference is indicated by italics and the bound variable reading in this case by subscription.)

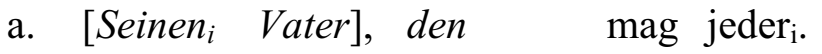 his-ACC father RP-ACC likes everyone
'His father, everyone likes.'
b. [СР seinen Vater C [TорР den mag-Top [тр jeder T...]]]

This example is from German and is typically known as "contrastive" left dislocation. Contrastive left dislocation stands in clear contrast to another type of left dislocation found in German (and English), known as "hanging topic" left dislocation (or nominativus pendens):

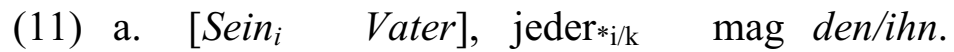 \\ his-NOMfather everyone likes RP/him-ACC \\ 'His father, everyone likes him.' \\ b. [CР sein Vater [СР C [тР jeder mag-T den/ihn...]]]}

Hanging topics appear in nominative, while the RP receives the "proper" Case. Moreover, the RP may appear low in the structure, as opposed to the topic position. What we see in (11) is that the bound variable reading from (10) disappears. If the left-dislocated constituent with the pronominal element inside has moved in one case, but not the other, this difference is predicted: at some point in the derivation (e.g. after reconstruction at LF), the quantifier and the pronoun are in a command relationship, allowing for variable-binding to take place.

It is easy to show that there exist clear contrasts between contrastive and hanging topic left dislocation beyond the one illustrated here. These have been known, debated and analyzed for a long time (see van Riemsdijk 1997 for an overview, and many papers in Anagnostopoulou et al. 1997, but also my own work in Grohmann 1997, 2000b, 2000c for discussion). 
In particular, the former construction does not display Weak Crossover or Condition A effects, but is sensitive to Condition C. Moreover, the two differ with respect to other consequences of reconstruction, such as the possibility of left-dislocating idiom chunks, whether they may appear in embedded contexts, and whether they allow multiple left-dislocated XPs.

Analytically, we could capture these differences as follows: contrastive left dislocation involves movement of the left-dislocated element (XP) through two Comp-positions - i.e. movement within the $\omega$-domain - and the RP is the spelled out copy that allows the (otherwise illegitimate) structure to conform to the CDE. Hanging topics, on the other hand, are basegenerated in a CP-adjoined position and the RP is inserted directly into derivation, not involving Copy Spell Out. The different structures are represented in the b-examples of (10) and (11); the relevant derivational steps for the former are shown in (12), where ' $\boldsymbol{~}$ ' indicates Copy Spell Out, a notation I will employ from now on throughout the paper.

(12) [ср seinen Vater C [торр seinen Vater $\vartheta$ den mag-Top [тр jeder T ... seinen Vater ...]]]

This leads us to the question what Copy Spell Out actually is. Intuitively, it "rescues" an otherwise illicit step in the derivation. Standard deletion of the lower copy within an anti-local environment (the same Prolific Domain) is ruled out by the CDE, but if the lower copy receives a different PF-matrix, the CDE is satisfied. Copy Spell Out doesn't delete, but spell out the lower copy, and by doing so assigns it a different PF-matrix (see Grohmann 2000a, 2001b for more).

Under the same assumption (i.e. that certain pronominal elements are grammatical formatives and that dependencies should be derived by movement wherever possible), another application of Copy Spell Out can be argued for local anaphors, where reflexives, for example, are the result of spelling out a copy that would otherwise violate the CDE. In other words, under such a view, local anaphors would also be introduced in the course of the derivation (see, for example, Lees \& Klima 1963, Lidz \& Idsardi 1997, Hornstein 2001a for precursors).

Parallel to (10) then, we could derive local anaphors just as RPs, via Copy Spell Out:

(13) a. John likes himself.

b. [те John T [ ${ }^{2}$ John $v$ [vP likes-V John $\vartheta$ himself]]]

Pronominal elements that surface as spelled out copies can thus be taken to be RPs of sorts, rescuing an otherwise illegitimate dependency. Or, in more general terms:

$$
*\left[{ }_{\alpha \Delta} \mathrm{XP} \ldots \mathrm{XP}\right], \text { unless } \mathrm{XP} \ni \mathrm{Y}, \text { where }[\mathrm{PF}] \text { of } \mathrm{XP} \neq[\mathrm{PF}] \text { of } \mathrm{Y}
$$

RPs thus seem to appear in two diametrically opposite environments, namely when a dependency would otherwise be too far (standard) or too close (Copy Spell Out); see also Grohmann \& Haegeman (in progress) for an elaboration of this point.

At this point, a puzzle materializes. Such a derivational account of reflexives raises the question how reflexive ECM-subjects might be derived. If (local) reflexives were always the result of Copy Spell Out within the same $\theta$-domain, it would not immediately be clear how himself could be introduced into the derivation in (15b):

(15) a. John expects Mary to win the race.

b. John expects himself to win the race. 
Under most standard assumptions, ECM-structures like (15a) would receive the following derivation:

(16) [Tе John T [ ${ }_{\nu \mathrm{P}}$ John $v$ [vр expects-V [Tе Mary to-T [vP Mary $v$ [vр win the race]]]]]]

However, given the abolishment of government as a configuration that licenses, among other things, Case-assignment, a minimalist approach to ECM-constructions needs to account for the "exceptional" accusative case-marking on ECM-subjects. There are basically three types of explanation available. First, the ECM-subject could covertly move to the matrix accusative position, such as SpecAgrOP (entertained by Chomsky 1991, Lasnik \& Saito 1993, among others); in this variant, the Case-features of the ECM-subject would be licensed at LF. Secondly, it could optionally move overtly to this position (advocated by a large body of "early" minimalist literature, up to Lasnik 1999, for example). Thirdly, the overt movement into matrix SpecAgrOP could be obligatory (as argued for by Koizumi 1993, 1995, Lasnik 1995a, 1995b, Bošković 1997, 2001, and others).

Either way we go, an approach that checks accusative case of the ECM-subject in the matrix clause would yield (17) as the underlying derivation for (15a), rather than (16) - where the relevant movement step takes place in the overt or covert component. ('?' is some position higher than AgrOP, given that the verb precedes the ECM-subject; further identification of '?' shall be of no concern - among other things, it also depends on how head movement is treated.)

\section{[тр John T [?P expects-? [AgrOP Mary AgrO [vP Jөhn $v$ [vP V [те Mary to win the race]]]]]]}

If local anaphors are the result of a domain-internal movement step (through Copy Spell Out applying to an otherwise illegitimate copy) and if matrix and ECM-subject are not part of the same thematic domain, in which this movement step could take place (viz. John likes himself), this domain-internal movement step could in theory occur at a later point.

To derive reflexive ECM-subjects, we could thus imagine one of the following derivations (only relevant parts shown), where the locus of Copy Spell Out is actually the matrix $\phi$-domain:

(18) a. [тP John expects [AgrOP John $\ni$ himself [vP John [vр [тP John to [vP John ... ]]]]]]

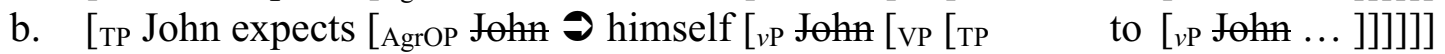

This route would allow us to hold fast onto the assumption that local anaphors are the result of Copy Spell Out, applying to the lower of two copies within one and the same Prolific Domain. The way local anaphors in simple clauses differ from anaphoric subjects of ECMcomplements is the type of Prolific Domain that hosts the relevant movement step: thematic vs. agreement domain. (We will discuss the difference between (18a) and (18b) in section 6.)

If this line of explanation is on the right track, we would have another argument that movement of the embedded subject of "deficient" complements (such as ECM-constructions, a notion we will pick up again later) into (the object position of) the matrix clause may take place overtly - after all, the reflexive ECM-subject in (15b) shows up as a reflexive at the point of pronunciation, thus the derivational step that results in Copy Spell Out must take place in the overt component. We can thus eliminate the hypothesis that such elements move exclusively in the covert component. 
One major goal of the remainder of the paper, the second part, will be to test how far we can take the nonchalant generalization in Grohmann (2000a) about the difference between intravs. inter-clausal movement, namely that across clause boundaries, movement always target the same type of Prolific Domain; this will be instrumental in helping us to decide on the derivation (18a) vs. (18b). But first let's turn our attention to small clause-/SC-syntax more diligently. ${ }^{4}$

\section{Small Puzzles}

When we turn to SC-complementation, a puzzle very similar to that seen in ECM-constructions arises: the SC-subject appears in nominative, it may be reflexive (bound by the matrix subject), and the matrix and the SC-subject never seem to appear in the same $\theta$-domain.

(19) a. Mary considers [John intelligent].

b. John considers [himself intelligent].

(20) a. Mary considers [John a good friend].

b. John considers [himself a good friend].

Just as above, we have to ask ourselves what the origin is of the reflexive subject of a small clause and how it gets Case. In the remainder of this paper, we will pursue this question and turn to the following topics:

(i) Can we account for reflexive SC-subjects derivationally (viz. Copy Spell Out)?

(ii) If so, or if not, what is the structure of SCs (relevant to the anti-locality framework)?

(iii) What types of movement does the anti-locality framework allow naturally (and why so)?

Again, we are faced with a number of possible approaches to capture SCs. The least interesting one, for current purposes, is that the anti-locality framework is simply barking up the wrong tree and the whole line of reasoning should be abandoned. Weaker versions of this argument could be that only the derivational analysis of local anaphors suggested here is untenable or that the particular analysis of reflexive ECM-subjects touched upon above is inappropriate. Under this view, SCs would receive the same structure that ECM-constructions used to receive (in GB), relevant to the current issue, namely something like the following:

(21) [тр John T [vР John $v$ [vр considers-V [xp himself (... himself ...) intelligent]]]]

"XP" denotes the SC, whatever structure it is made up of (see fn. 4 above and also section 5 below), and Case is checked in whatever way Case is checked (e.g. under "government," as in GB). The reflexive is licensed in whatever way local anaphors are licensed (subsumed under Condition A, for example). For obvious reasons, I will not entertain this option any further, but push a line very much compatible with the anti-locality framework, and naturally so, as I argue.

4 I use "SC" to denote the small clause in general (not its category), regardless of its finer architecture (cf. (24)). 
An alternative would hold that SCs essentially behave like standard ECM-complements: the SC-subject undergoes movement into the matrix clause object position, as sketched above for ECM-constructions - overtly or covertly (with emphasis on the former):

(22) [тр John T [AgrOP himself AgrO [vP John $v$ [vp considers-V [xp himself intelligent]]]]]

However, this still doesn't account for the "introduction" of the reflexive, if it is really "introduced" into the derivation, rather than base-generated and licensed by more traditional means. This can be achieved if reflexive SC-subjects actually behave like reflexive ECMsubjects in an anti-locality framework: they undergo Copy Spell Out in the matrix $\phi$-domain.

If this line of reasoning is correct, reflexive SC-subjects would be introduced the same way that reflexive ECM-subjects are introduced in the anti-locality framework, namely by moving first into the matrix $\theta$-domain, then into some position of the matrix $\phi$-domain ("AgrOP"), and finally to another position within the matrix $\phi$-domain ("TP"), undergoing Copy Spell Out. We could illustrate the necessary steps roughly as follows:

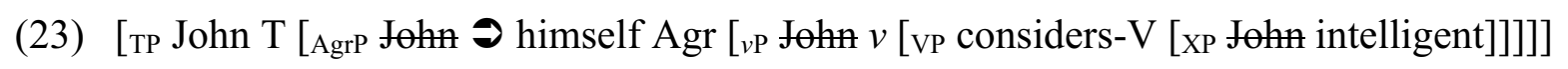

This is very similar to what we have seen in (18a) vs. (18b) above. One apparent difference is, of course, that the internal structure of a SC is not the same as that of an ECM-complement. While the latter is presumably a full-fledged (if deficient) TP, the former has been argued to be something different. For ECM-clauses it is easy to see that they contain a $\theta$-domain as understood from (8): they include a full verbal predicate, without restrictions; they can also be argued to contain a $\phi$-domain, indicated by to. Arguably, this non-finite TP/ $\phi$-domain is deficient (in the standard sense, i.e. at least in as far as it fails to license nominative). One goal of the following discussion is to decide on the status of "XP" in (23). If the SC-subject overtly moves into the matrix clause, (i) which position (Prolific Domain) does it target and (ii) where does it come from? Aside from a comparison of the syntax of ECM- and SC-subjects, we will thus investigate the finer structure of SCs, as relevant to the anti-locality framework. We will then adopt some version or refinement of the derivation in (23), which we will then generalize (in terms of the above-mentioned distinction between "intra- vs. inter-clausal movement").

\section{Small Clauses}

A standard characterization of a small clause is that it forms the minimal structure expressing predication, without containing tense. What is relevant for our purposes is the question of what this "minimal structure" could or should look like in an anti-locality framework (such as the one presented here), one that splits the clause into Prolific Domains. What we will investigate next is thus what the internal structure of SCs looks like and how it connects beyond the SCcomplement, i.e. how it interacts with the matrix clause.

The literature is split about the "constituency question" of SCs. A large body, since Jespersen (1924), has assumed that the SC-complement (subject and predicate) are generated as a constituent, the view endorsed here. Other approaches, however, deny such a constituent relation 
(e.g., Bresnan 1978, Williams 1983, Schein 1995) or derive it as a result of complex predication (Chomsky 1955). I will concentrate on various approaches within the first-mentioned camp for two reasons: first, for reasons of space and second, it seems to work (applied to anti-locality).

Three typical instantiations of the SC-as-constituent approach are given in (24):

(24) a.

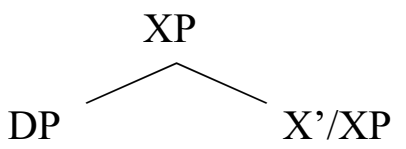

b.
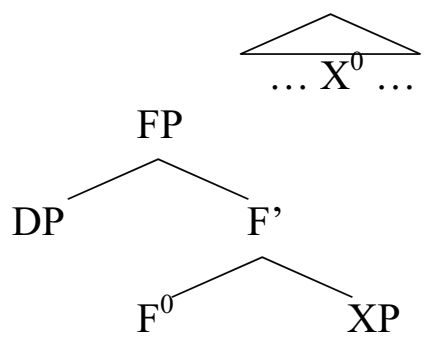

c.

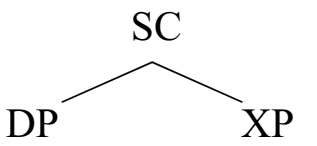

Under the variant in (24a), the subject of the small clause (DP) is taken to be the specifier of a predicative head $\mathrm{X}^{0}$ (Stowell 1981, 1983); alternatively, it is adjoined to the predicate XP (Manzini 1983, Heycock 1994, Rothstein 1995). The entire small clause is an XP. In (24b), a small clause is understood to be the projection of a special functional head, such as "Pred" (Bowers 1993) or "Agr" (Guéron \& Hoekstra 1995); see also Moro (1988), Svenonius (1994), Pereltsvaig (2001) for more discussion. (24c), finally, takes a small clause to be of the type "SC" with the bare structure [sc DP XP], as argued for by Moro (1997, 2000). This approach thus assigns the construction SC the categorial status SC (cf. fn. 4).

Regardless which one of the approaches in (24) we choose (or any other, for that matter), something has to be said in addition to the structure of SCs concerning how they tie in with higher (possibly predicative) material. Two relevant questions in this respect are the following:

(i) Is there movement within the SC before moving to a higher clause?

(ii) Is there movement from the SC to some higher position before moving to a higher clause?

I want to treat the exact internal structure of a SC the same way I treat the exact internal structure of INFL or COMP: rather vaguely with respect to the projections involved and finer architecture, focusing on the input of Prolific Domains and the relevance of the anti-locality framework. There are three relevant hypotheses we could consider:

(H1) SCs constitute their own individual Prolific Domain (i.e. an additional one).

(H2) SCs constitute one separate Prolific Domain of the three available (e.g. $\theta$-domain).

(H3) SCs constitute more than one separate Prolific Domain (maybe a $\theta$ - and a $\phi$-domain).

As before, I'll pick the last hypothesis, walk with it and mold it. This will allow us then to be more specific with respect to the internal structure of SCs. Maybe we will be able to decide on (24a-c) a little bit more precisely. 


\section{Small Analysis}

One primary goal will be to explain the accusative case of the SC-subject and the derivation of reflexive SC-subjects, relate it to other structures (such as ECM), and generalize the typology of movement steps in an anti-locality framework. Before we settle for one of the three hypotheses (H1-3), let's then consider two generalizations concerning movement and the computation within an anti-locality framework, namely movement within a clause ("intra-clausal") and across clause boundaries ("inter-clausal"). ${ }^{5}$

Considering the relevant copies of a moving Wh-phrase indicated in (25b), needed for Whmovement (i.e. checking thematic, agreement and discourse features), we can generalize all (argument) movement within a given clause: it must take place from a $\theta$ - to a $\phi$ - and, if needed, to an $\omega$-position. In other words, intra-clausal movement always targets the next higher Prolific Domain in the clause, as expressed in the abstract derivation (25a).

(25) Intra-clausal movement hypothesis

a. $\left[{ }_{\omega \Delta} \ldots \mathrm{XP} \ldots\left[{ }_{\phi \Delta} \ldots \mathrm{XP} \ldots\left[{ }_{\theta \Delta} \ldots \mathrm{XP} \ldots\right]\right]\right]$

b. Who did Mary whe see whe?

Movement across clauses is characterized by the successive-cyclic property, which has long been argued for. Standardly employed in long Wh-movement or A-raising, this is nothing new. Given what we have just said, that a wh-phrase needs to check the three relevant types of features, (26a) is an appropriate, if abstract, derivation for (26b), indicating all relevant copies of the Wh-phrase that undergoes A-raising prior to Wh-checking.

Inter-clausal hypothesis

a. $\left[{ }_{\omega \Delta} \mathrm{XP} \ldots\left[\left[_{\phi \Delta} \mathrm{XP} \ldots\left[{ }_{\theta \Delta} \ldots\left[{ }_{\omega \Delta} \ldots\left[\left[_{\phi \Delta} \mathrm{XP} \ldots\left[{ }_{\theta \Delta} \ldots\left[{ }_{\omega \Delta}\left[{ }_{\phi \Delta} \mathrm{XP} \ldots\left[{ }_{\theta \Delta} \mathrm{XP} \ldots\right]\right]\right]\right]\right]\right]\right]\right]\right.\right.\right.$

b. Who whe seems whe to be likely whe to whe sleep?

Let's assume that the two hypotheses regarding intra- and inter-clausal movement have some bearing on the computation of standard accounts of locality effects and anti-locality. (Again, see Grohmann 2001b for more.) We can now turn to an evaluation of (H1-3).

The first hypothesis takes an SC to be its own Prolific Domain, a type of Prolific Domain different from the three established so far. Call it $\beta \Delta$, just to distinguish it from the others. Recall our agenda from section 4 that derives accusative-marking on the SC-subject by (overt or covert)

5 In the interest of space, this discussion must be cut short. A more extensive treatment can be found in Grohmann (2001b), where these hypotheses, treated as the "Intra-Clausal Movement Generalization" and the "Inter-Clausal Movement Generalization," respectively, are formulated abstractly as follows:

(i) a. Intra-Clausal Movement Generalization $\left[{ }_{\beta \Delta} \mathrm{XP} \ldots\left[{ }_{\alpha \Delta} \ldots \mathrm{XP} \ldots\right]\right]$, where $\beta>\alpha$

b. Intra-Clausal Movement Generalization $\left[\alpha \Delta\right.$ XP ... $\$$. [ $\alpha_{\Delta} \ldots$ XP ...]], where $\ddagger=$ clause boundary

Space doesn't permit a more thorough discussion. What I will do here is assume that these generalizations have theoretical and empirical merit. As such I am going to employ them to tease apart potential analyses, but refer to them as hypotheses, for the time being axiomatically helpful but no proven warranty. 
movement into the matrix $\phi$-domain (AgrOP). If (27a), repeated from (23), is our specific derivation, (27b) should be the one relevant for an evaluation from the perspective of the antilocality framework, where XP is our small clause-complement SC (whose structure has yet to be determined):

(27) a. [те John T [AgrP Jøhn $\vartheta$ himself Agr [vP John $v$ [vр considers-V [XР Jøhn intelligent]]]]

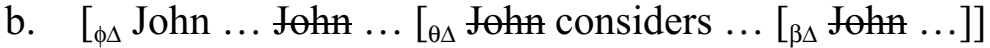

(H1) now make two particular predictions in the current context: movement within a SC should be illicit (as a CDE-violation), and our hypothesis concerning inter-clausal movement would have to be extended. I take it that compared with (27), (28) would be the desired structure for a clause with a SC-complement whose subject is not reflexive, where the SC-subject still needs to move to SpecAgrOP/ $\phi$-domain of the matrix clause to check accusative:

(28) a. [тр Mary T [AgrP John Agr [vр Mary $v$ [vр considers-V [xp John intelligent]]]]

b. [ ${ }_{\phi \Delta}$ Mary ... John ... [ ${ }_{\theta \Delta}$ Mary considers ... [ ${ }_{\beta \Delta}$ John ...]]

The movement from the SC $\beta$-domain to the matrix $\phi$-domain does not conform in any obvious way to the inter-clausal movement hypothesis. It would have to be modified so as to capture that from an additional Prolific Domain $\beta$-domain, movement may target (at least) either a position within the $\theta$-domain or the $\phi$-domain of the next higher clause. This is only one argument against the existence of " $\beta \Delta$," on top of conceptual reasons, evoking an additional tool in our inventory for (so far) no compelling or reasons of (virtual) conceptual necessity.

Let's turn to (H2). On analogy with (27) for (H1), (29) is presumably the counterpart for this hypothesis, where " $\alpha \Delta$ " is the Prolific Domain that specifies XP (our SC-complement), which is of one of the three types in our inventory $(\theta \Delta, \phi \Delta$ or $\omega \Delta)$.

(29) a. [TP John T [AgrP John $\ni$ himself Agr [ ${ }_{\mathrm{vP}}$ John $v$ [vр considers-V [xp John intelligent]]]]

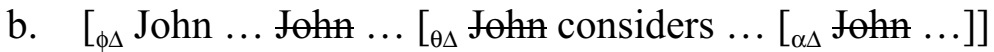

The predictions from this hypothesis are for one also that no movement should be possible within the SC-complement, but in addition that movement outside the SC should target a $\theta$ domain, should we identify " $\alpha \Delta$ " with the $\theta$-domain. The latter prediction looks good for (29), but fares less well with a non-reflexive SC-subject, as in (28a). If " $\alpha \Delta$ " is indeed the $\theta$-domain, this movement runs again counter the inter-clausal movement hypothesis.

Alternatively, we could assign a varying identification of " $\alpha \Delta$ ": it could be a $\theta$-domain if the $\mathrm{SC}$-subject is (to become) a reflexive and a $\phi$-domain elsewhere. The obvious fault of this step is that Prolific Domains are not some purely formal marker without any meaning. As the nature of a given Prolific Domain is regulated by the contextual information it encodes, it is highly unlikely that one and the same structure - a predicative SC - should be one of two different Prolific Domains, more or less at choice. On the other hand, given that SCs are predicative, it lies near to assign it the Prolific Domain that specifies thematic information, i.e. the $\theta$-domain. Let's do that next.

(H3), namely, says that SCs are more complex than a single Prolific Domain. It suggests that a SC - again, with a finer articulated structure yet to be decided upon - comprises two Prolific Domains. If one is the $\theta$-domain for the reasons just given, it is likely that the second one 
would be the $\phi$-domain, the next higher one (viz. the intra-clausal movement hypothesis from above). Applying this reasoning to the two exemplary cases (27a) and (28a), we yield the following structures, the (H3)-counterparts of (27b) and (28b), respectively:

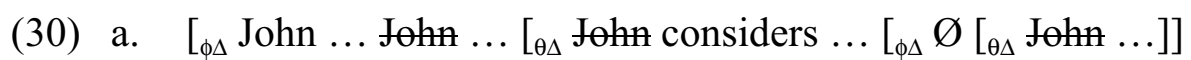

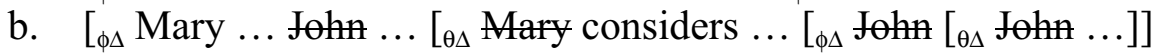

What we see here is the following. A reflexive $\mathrm{SC}$-subject undergoes (inter-clausal) movement from its base-generated SC-position, a predicative $\theta$-position, straight into the matrix $\theta$-position (before moving on into the matrix $\phi$-domain). A non-reflexive SC-subject, however, undergoes $\mathrm{SC}$-internal movement - ruled out by both $(\mathrm{H} 1)$ and $(\mathrm{H} 2)$ - from its base-generated $\theta$-position to an additional SC-internal position, within the $\phi$-domain of the SC. Once there it can (only) target a matrix $\phi$-position, and everything is hunky-dory.

This option forces us to adopt an alternative similar in spirit to the one mentioned for (H2) above. The difference is, however, that in the previous alternative suggestion we would have to assume two different structures for the SC-complement, while under this strategy the SC is invariantly bi-domainic; the option that arises under $(\mathrm{H} 3)$ is whether or not to move through the $\phi$-position of the SC. In other words, the prediction that (H3) makes is also two-fold, but very different from the other hypotheses: SC-internal movement should be fine (as we now have two Prolific Domains) and additional movement should target either the matrix $\theta$ - or the matrix $\phi$ domain (depending on the launching position). I opt for (H3) in general, and the domain-relevant derivations in (30a-b) for (27a) and (28a), respectively (i.e. (19a-b) from section 4 above).

This optionality might raise an eyebrow or two, so let's go through the background assumptions particularly implied in the inter-clausal movement hypothesis. We will see that the proposal that the SC-subject may, but need not, move through an intermediate position is not unreasonable. Moreover, there are other constructions that exhibit exactly this kind of optionality (which, I argue, is not "optionality" at all).

Consider a derivational approach to control constructions, such as the one advocated recently by Hornstein $(1998,1999,2001 a, 2001 b){ }^{6}$ Taking minimalist desiderata seriously to try and simplify the inventory of tools, conditions, assumptions and so on, Hornstein scrutinizes a number of modules internal to the language faculty that were part of GB theory. One of these, the Control Module (including the PRO theorem) is particularly suspect. Not only because as a "module" it better be something needed for virtual conceptual necessity; following the usual Ockham's razor arguments, a module constitutes additional machinery that should only exist if it really gives us much - and if it doesn't, and if its effects can be explained otherwise (with the help of existing assumptions), it should be abolished. (Besides that, PRO is also identified by concepts that don't play a role anymore, in particular the requirement that PRO be ungoverned.)

Thus, we could either develop a minimalist version of government and restate this condition - not a satisfactory option for obvious reasons. Or we could find another (type of) requirement that explains the identification, distribution and licensing of PRO - such as the Null Case approach (cf. Martin 1996, extending a proposal from Chomsky \& Lasnik 1993).

\footnotetext{
I concentrate on Hornstein's specific proposals, as it's (a) couched in a minimalist framework, (b) assumes a very similar view of the grammar as endorsed here, and (c) is very compatible with the anti-locality framework. In fact, the anti-locality framework supports his particular analysis without postulating additional machinery. (A movement approach to control, relating similarities between it and raising, goes back to Bowers 1973, 1981.)
} 
Alternatively, we can look at the properties of PRO and examine whether, in the absence of a government relation and so on, we can reduce it to already existing entities — such as those objects left behind by movement, i.e. a copy of (NP-) movement. This is the line that Hornstein embarks on and develops (see also O'Neil 1995, Manzini \& Roussou 2000). Relevant for us is an analysis in terms of movement - for both raising and control. Let's review this very briefly.

Raising and control constructions exhibit a number of obvious similarities: they both involve a non-finite complement clause whose subject position is phonetically empty; that subject receives its interpretation from the filled subject position in the finite matrix clause. The main difference, to be derived in a movement analysis, is that the control dependency between the overtly filled matrix and the empty embedded subject involves with two theta-roles, but the raising dependency only one.

The movement analysis of control put forward by Hornstein is movement of the embedded subject from its (thematic) agent-position to the matrix agent-position - movement into a $\theta$ position. He considers both (31a) and (31b). The former assumes the intermediate step for reasons of the EPP (originally entertained in the beginning of chapter 2; cf. Hornstein 2001a: 27, 38). The latter follows Castillo, Drury \& Grohmann's (1999) doubts about the EPP, dispenses with that step and moves the subject in one fell swoop as, what we would call, $\theta$-to- $\theta$-movement (adopted in the remainder of the book; cf. Hornstein 2001a: ch. 2, esp. pp.56f., and p.223, fn.12).

(31) a. [тр John T [ ${ }_{\nu \mathrm{P}}$ John wants [тр John to [vP John win the race]]]]

b. [Tе John T [vP John wants [TP Ø to [vP John win the race]]]]

From the point of view of the inter-clausal movement hypothesis, (31b) would fit the pattern. Moreover, if the EPP does not exist (see also Epstein \& Seely 1999, Boeckx 2000, Grohmann, Drury \& Castillo 2000 for discussion), the intermediate touch-down would not be required a priori. On the other hand, we would like this intermediate touch-down to happen in raising for the same reason (i.e. following the inter-clausal movement hypothesis). We have basically three choices, in both control and raising (not necessarily mutually exclusive):

(1) passing through non-finite SpecTP is enforced by the EPP

(Chomsky 1981, 1982 and all "standard" approaches since)

(2) the EPP doesn't exist, hence the intermediate SpecTP is empty

(Epstein \& Seely 1999, Boeckx 2000, Grohmann, Drury \& Castillo 2000)

3 the intermediate EPP doesn't exist, but the position is filled for locality reasons

(see Grohmann 2000a, 2001b for current and Bošković 2001 for independent reasons)

Only 3 fits with the working hypothesis of intra- vs. inter-clausal movement. As just mentioned, control verbs have a full thematic structure or $\theta$-domain (containing $v \mathrm{P}, \mathrm{VP})$. Hence $\theta$-to- $\theta$-movement as in (31b), repeated here, would indeed be an appropriate option:

(32) a. John wants to win the race.

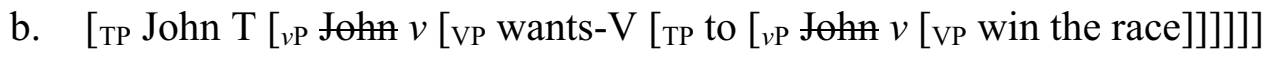

Raising verbs, on the other hand, lack a full thematic structure; presumably the $\theta$-domain of this class of verbs contains only a bare VP. From the point of view of the inter-clausal movement hypothesis, $\phi$-to- $\phi$-movement should apply here, as sketched below: 
(33) a. John seems to win the race.

b. [Tт John T [vp seems-V [TP John to [ ${ }_{\mathrm{pP}}$ John $v$ [vP win the race $\left.\left.\left.]\right]\right]\right]$

The embedded SpecTP of “deficient” (i.e. non-finite) T isn't filled for EPP-reasons, but for locality (or so argues Bošković 2001). Consider (34):

(34) a. John was considered a fool.

b. * John was considered himself a fool.

Passive verbs can be argued to lack $v \mathrm{P}$, thus force movement from embedded structures into their (matrix) $\phi$-position. If they lack thematic positions, movement into the $\theta$-domain of a passive verb is not expected. Following all we have said so far, (34b) is thus correctly ruled out:

\section{[TP John was-T [vp considered [ ${ }_{\phi \Delta}$ John $\phi$ [sC John a fool]]]}

Returning to the above-mentioned "optionality," we can now record that no intrinsic property of (deficient) $\mathrm{T}$ forces movement to or through its specifier position. If this position can be filled or not - depending on a certain understanding of (standard) locality considerations (Bošković 2001) — we would like to see how it can be skipped in some cases. The inter-clausal movement hypothesis would offer a possible principled account. ${ }^{7}$ It takes the status of the moving element seriously: if it needs to move into a higher $\theta$-position, it can only do so from a $\theta$-position; this yields control structures and dispenses with the intermediate touch-down. If the intended movement targets a higher $\phi$-position, it can only take place from a $\phi$-position; this gives us raising, where the matrix (raising) verb doesn't even make a $\theta$-position available, and movement to deficient SpecTP is necessary. This is an instance of potential points of symmetry between standard accounts of locality and this framework (see Grohmann 2001b).

To recap, within a framework that takes a tripartition of the clause seriously (formalized in terms of Prolific Domains) we saw that it makes sense to treat small clause- (SC-) constructions to comprise not one, but two Prolific Domains, which we identified as the $\theta$ - and the $\phi$-domain. Reasons for this are two-fold. First, following the Condition on Domain-Exclusivity (CDE), elements in the phrase-marker cannot move within a given Prolific Domain, or rather, no dependency can be formed between two positions in one and the same Prolific Domain which are assigned identical PF-matrixes. This constitutes the gist of what we have called the antilocality framework throughout. If correct, it means that the subject of SC-complements, which must raise to the matrix object position, should not be able to move within the SC, unless the SC is bigger than a single Prolific Domain.

Second, on analogy with a derivational approach to reflexivization applied to ECMsubjects, we found it useful to have the option of moving the SC-subject into the matrix $\theta$ position, from which it can then proceed to the object and the subject positions, spelling out its copy in AgrOP as the reflexive (otherwise, the CDE would be violated). This derivation would

\footnotetext{
If there is something to the intra- and inter-clausal movement hypotheses (see fn. 5), we would, of course, like to derive these somehow, rather than state them axiomatically. A potential route of explanation might involve a closer examination of the Uniformity Condition, usually expressed over chains (see Browning 1987 and Chomsky \& Lasnik 1993, Chomsky 1993, among others, for further discussion). I leave the discussion at that, with a final note that such an explanation of the intra- and inter-clausal movement hypotheses/generalizations is not worked out in Grohmann (2001b) either.
} 
conform to our proposal of deriving reflexives as the result of copy Spell Out within a given Prolific Domain. On the basis of the inter-clausal movement hypothesis we saw that in this case, the SC-subject must move from its base-generated position into the matrix $\theta$-domain, while in non-reflexive cases, it must move through an intermediate position within the SC. (I underline the warning for caution that this hypothesis is only that, a hypothesis, as mentioned in fn. 5; however, it seems to fit in with the present framework, the cases at hand, and many other cases.) We discussed several possibilities for the types of Prolific Domain(s) involved in SCs and reached the conclusion that it must be one $\theta$ - and one $\phi$-domain.

\section{$7 \quad$ Small Structures}

In the final section, I want to consider a number of other aspects that concern the structure of SCs. As before, I'll concentrate on the input of the anti-locality framework, i.e. on the domainrelevant structure. A bit of musing towards the end will allow us, though, to say a little bit more about the options for more specific structure as the discussion around (24) implied.

An interesting phenomenon relevant for this discussion is a construction that Rafel (2000) calls "complex small clause" (CSC), illustrated for English in (36).

(36) a. I regard [John as my best friend].

b. They took [John for a fool].

Rafel takes a CSC to be an instance of double predication, where one SC (XP in (38)) is predicated of another one (YP). The resulting structure is a mirror image of the structure of "simple" SCs (cf. (24a-c)).

\section{$\left[\mathrm{XP}=\mathrm{CSC} \mathrm{DP}_{\mathrm{i}}\left[\mathrm{X}, \mathrm{X}\left[\mathrm{YP}=\mathrm{SC} \mathrm{PRO}_{\mathrm{i}} \mathrm{Y}\right]\right]\right]$}

We will discuss the plausibility of the existence of CSC as such next. First bear in mind, however, that we still haven't decided which option of (24a-c) to take. Rafel's structure in (38) suggests either (24a) or, more likely and in the spirit of Rafel's proposal, (24b), where some functional head takes YP as its complement and XP as its specifier. Refraining from further discussion of the structure of a CSC for the time being, Rafel argues that the head X can stand for different heads, such as complementizer C, as illustrated in (38):

(38) a. I regard $\left[\mathrm{CP}=\mathrm{CSC} \mathrm{John}_{\mathrm{i}}\right.$ as- $\mathrm{C}\left[\mathrm{SC} \mathrm{PRO}_{\mathrm{i}}\right.$ my best friend] $]$

b. They took $\left[\mathrm{CP}=\mathrm{CSC} \mathrm{John}_{\mathrm{i}}\right.$ for-C $\left[\mathrm{SC}_{\mathrm{PRO}}\right.$ a fool] $]$

Note that this exact structure should raise suspicion, at least for the reason that it contains PRO. If we wanted to adopt Rafel's analysis, we should look for a derivational implementation in the current framework. Moreover, the fully clausal ("CP") analysis of the embedded (C)SCstructure isn't compatible with our assumptions: if CSC were indeed CP, then it should constitute its own $\omega$-domain. If that were the case, how could John then move into the matrix $\theta$-position (again, holding fast to the inter-clausal movement hypothesis)? 
I want to offer and discuss three alternatives to analyse CSCs. One would be to treat the "complex" part (i.e. YP) as an additional Prolific Domain on top of the "simple" SC. This would be a $\theta$-domain, clear if we treat as and for as the predicative elements. In other words, "complex" SCs would be complex because they constitute two "simple" SCs. This strategy is illustrated in (39b), compared to the "simple" SC in (39a):
a. $\mathrm{V}\left[{ }_{\phi \Delta} \ldots \ldots\left[{ }_{\theta \Delta} \mathrm{DP} \mathrm{XP}\right]\right]$
(viz. Mary considers John intelligent.)
b. $\mathrm{V}\left[{ }_{\phi \Delta} \ldots \ldots\left[{ }_{\theta \Delta} \mathrm{DP}_{\mathrm{i}}(\right.\right.$ as $/$ for $\left.\left.)\left[{ }_{\theta \Delta} \mathrm{PRO}_{\mathrm{i}} \mathrm{XP}\right]\right]\right]$
(viz. Mary considers John as her friend.)

$\mathrm{DP}$, the SC-subject, would in these cases raise into the slot within the $\phi$-domain marked '_ ' (and straight into the matrix $\theta$-domain if it is reflexive). One advantage, and hence a potential means for evaluating the options suggested here, is that this allows a movement analysis of the DP-PRO relationship that Rafel assumes. If PRO boils down to being a copy left behind by movement from a $\theta$ - to a $\theta$-position, we don't run into trouble.

An alternative would be to say that the "complex" part is a $\phi$-domain on top of a $\theta$-domain. The $\theta$-domain would be then be the original SC.
a. $\mathrm{V}\left[{ }_{\phi \Delta} \ldots \ldots\left[{ }_{\theta \Delta} \mathrm{DP} \mathrm{XP}\right]\right]$
b. $\mathrm{V}\left[\phi \Delta \_a s /\right.$ for $\left.\left[{ }_{\theta \Delta} \mathrm{DP} \mathrm{XP}\right]\right]$
(viz. Mary considers John intelligent.)
(viz. Mary considers John as her friend.)

This allows us to keep the same structure for SC and CSC in terms of Prolific Domains: both contain one $\theta$ - and one $\phi$-position, instead of two $\theta$-positions (and presumably another $\phi$ domain on top) form the first option. Unlike the first option, however, this alternative doesn't allow for a movement analysis of PRO. But it doesn't need to: given that control is movement across Prolific Domains, the constructions considered here cannot distinguish between movement of the sort we would apply to $(39 \mathrm{~b})$, from one $\theta$ - to another $\theta$-position (recreating $\mathrm{PrO})$, but as we indicated in (40b), from the base-generated $\theta$-position ('DP') to the $\phi$-position ('_'), i.e. A-movement business as usual.

Whether the first or the second option fare better (or even which one would be more plausible) shall play no role. There is a third option, and our empirical testing case which we'll see presently is one which cannot be captured by either the first or the second option. The third option can, so it is the one I adopt. This options says that the "complex" part is no additional material beyond the original "simple" SC, but it plainly is part of the original $\theta$-domain. Thus, CSCs and SCs are structures that are base-generated within a single $\theta$-domain with a single $\phi$ domain on top — with respect to Prolific Domains completely identical:
a. $\mathrm{V}\left[{ }_{\phi \Delta} \ldots \ldots\left[{ }_{\theta \Delta} \mathrm{DP} \mathrm{XP}\right]\right]$
b. $\mathrm{V}\left[{ }_{\phi \Delta} \ldots \ldots\left[{ }_{\theta \Delta} \mathrm{DP}(\right.\right.$ as/for $\left.\left.) \mathrm{XP}\right]\right]$
(viz. Mary considers John intelligent.)
(viz. Mary considers John as her friend.)

This treatment of "complex" SCs is basically the line taken by Moro (1997). ${ }^{8}$ Once again the last alternative seems to be most compatible (possibly coupled with (ib) from fn. 8). Consider the following data:

\footnotetext{
8 In fact, Moro argues against a layered SC-structure, as the first two options in the text above would imply. The structures he suggests are the following (slightly adopted for current purposes):
} 
(42) a. They took [John for a fool].

b. John took [himself for a fool].

(43) a. They took [John for himself].

b. John took [himself for himself].

While (42) could be analysed under either option (cf. (44)), (43) shows that we must allow SC-internal movement to derive a reflexive in the "simple" part of "complex" SCs. Following the discussion up to this point, the most likely derivation for (43b) would be (45):

(44) a. [TP they [AgrP John [vP they took [SC John for a fool]]]]

b. [Tт John [AgrP John $\vartheta$ himself [vP John took [sC John for a fool]]]]

(45) a. [Tе they [AgrP John [vр they took [sC John for John $\ni$ himself]]]]

b. [тр John [AgrP John $\vartheta$ himself [vр John took [sC John for John $\vartheta$ himself]]]

As there is presumably no way that we could argue the lowest occurrence of himself in these cases to move into the matrix clause, it must be generated (or derived via Copy Spell Out) internally to the SC. This means that John, the original (and only) DP in (43b), must move from one position to another position within the same Prolific Domain. In order to "become" a reflexive (again), it must also move into the matrix $\theta$-position. This suggests that John leaves the $\mathrm{SC}$ from a $\theta$-position (by the inter-clausal movement hypothesis). In other words, the structure of the "complex" SC-complement in (43b), marked simply SC in (45b), has the same structure as any "simple" SC we have seen so far, regardless of the presence of for.

Under these considerations, the domain-relevant structure of (45b) is (46):

(46) $\left[_{\phi \Delta}\right.$ John John $\odot$ himself [ ${ }_{\theta \Delta}$ John took $\left[_{\phi \Delta} \varnothing\left[{ }_{\theta \Delta}\right.\right.$ John for John $\odot$ himself $\left.\left.]\right]\right]$

After all this discussion of domain-relevant aspects of the structure of SC-complements, note that we still haven't decided on the categorial status of SCs from (24a-c) above. Ideally, I'd leave it at that, but I feel compelled to at least discuss some aspects of the structures mentioned. While we cannot yet satisfactorily decide on any single one, we should be able to rule out some, on pretty much principled grounds in the current framework. I leave it to the reader to decide in how far the argument goes through, as I don't believe that a resolution matters for the main point argued for.

As we noted repeatedly, a Prolific Domain is not simply a technical gimmick, but relates to contextual information in the guise of thematic properties. The current framework clearly dissociates thematic from agreement properties and as such pin-points the locus of Case- and $\phi-$ feature checking beyond the thematic layer unambiguously. This dissociation is muddled under "standard" recent approaches, since section 4.10 of Chomsky (1995). That line of research

(i) a. [sc DP (as) XP] (Moro 1997: 203, ex. (104))

b. [sC DP [asP as XP]] (Moro 1997: 287, n.31, ex. a)

c. [asP DP [as' XP]] (Moro 1997: 287, n.31, ex. b)

Option (ib) is the more general one, disregarding details about the position of as (or for), but he notes that in (ib) "as is entirely parallel to of in of-insertion." 
pursues Case-checking through some property of $v$, by creating an additional specifier to $v \mathrm{P}$ where accusative gets licensed. This is not the right place to discuss multiple specifiers (see Grohmann 2001a for discussion and references). But what this muddling amounts to is to allow a potential mixing of $\theta$ - and $\phi$-properties. This might be the right way; after all, Koizumi (1993, 1995) originally suggested splitting the verbal layer into iterative VP-AgrP structures (the "Split VP-Hypothesis"), mixing them uniformly (see also Lasnik 1995b). But it would be incompatible with the anti-locality framework laid out here.

The suggestion that SCs are generated in a structure like (24b) has often been followed by identifying the head $\mathrm{F}$ with a particular functional head, such as Asp(ect) or Agr(eement), as mentioned above. This seems to be the same type of muddling as licensing accusative on $v$ : for all purposes, Asp and Agr are $\phi$-related and not uniquely predicational or thematic. As such, they're not predicated to be part of a $\theta$-domain, but as the discussion above has argued ad nauseam, this is the kind of Prolific Domain that we need.

The first suggestion, (24a) comes in two flavours, as also briefly mentioned above. Generating the SC-subject as an adjunct or as a specifier. For reasons laid out elsewhere (such as Grohmann 2000a:80-112, 2001a), structurally adjuncts make very poor candidates for as tight predication relations as we are dealing with in SC-constructions. If we choose the specifier option, we would again have to say something about the head X, projecting XP — and if the answer is one along the lines of "F" just discussed, we can dismiss it on the same grounds.

This leaves us with two other options. The subject is generated as a specifier of a head X, and $\mathrm{X}$ is clearly and uniquely thematic in nature; or the entire SC is formed by merging the subject DP and the predicate XP. A lot of background information hangs on both choices, so I will leave the discussion at that. For the anti-locality framework as presented here it doesn't matter whether we're dealing with [sC DP XP] or [xp DP [x, YP]], as long as both can be shown to be possible $\theta$-domains.

Now that we have considered the domain-relevant structure (and, to some degree, the categorial status) of SCs in quite some detail, let's revisit control, one more time. We could ask ourselves why control verbs don't take SC-complements (Williams 1994, Schein 1995):
a. * John persuaded Bill [PRO happy].
b. * John tried [PRO happy].

The explanation seems to be that SC-selecting verbs assign nominative and accusative (cf. ECM-believe), while control verbs don't. Note that Hornstein (2001a: 158) also remarks that verbs may differ as to whether they discharge accusative case or not. Thus, verbs like expect optionally assign case, in which case they function as ECM-verbs. When they don't, they are used in their control-verb function.

(48) a. John expects himself to be elected.

b. John expects PRO to be elected.

The relevance of Case here is obvious: as both (48a) and (48b) involve movement of John in the present framework, the ad hoc character of the "optional" movement of John (either into a $\theta$ - or into a $\phi$-position) is accounted for.

Verbs like believe, on the other hand, do not have this option. they must assign accusative case: 
(49) a. John believes himself to be elected.

b. * John believes PRO to be elected.

The explanation I would like to suggest goes as follows. Expect-type verbs may assign nominative and accusative, believe-type verbs only nominative. Thus for expect there are two derivational choices. The embedded agent may become the matrix agent and then check both accusative and nominative (with the result that one of the two "becomes" an anaphoric element, viz. copy spell Out, forced by the CDE). Alternatively, the embedded agent becomes the matrix agent and then check nominative only; in this case the matrix subject/agent "controls" the embedded subject/agent. In the other case, we only have one option. Agents that are embedded within complement clauses of believe may only become the matrix agent, in which case they check nominative.

Let's sum up the main results of this paper. At least with respect to a clausal tripartition in terms of Prolific Domains, the behaviour of SC-subjects suggests that ECM- and SCconstructions should be analysed on a par. Both involve obligatory movement of the embedded subject into a matrix Case position. For ECM-constructions, this is fairly standard. The relevant (abstract) derivation for sentences like (50) are given in (51):

(50) a. John expects Mary to win the race.

b. John expects himself to win the race.

(51) a. $\quad[\phi \Delta$ subject ... DP ...

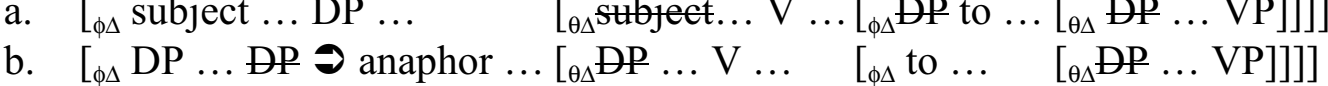

As we have argued, SC-constructions underlie the same derivational steps. Note that while the embedded structure arguably differs from ECM-structures in terms of projections, they share the same number and types of Prolific Domains, one $\theta$ - and one $\phi$-domain. Thus, the relevant derivations for SCs, like (52), are the same as the ones for ECM-constructions; (53) and (51) are virtually identical (differing only in the embedded predicate):

(52) a. John considers Mary intelligent.

b. John considers himself intelligent.
a. $\quad[\phi \Delta$ subject $\ldots$ DP $\ldots$
$\left[{ }_{\theta \Delta}\right.$ subject... V ... $\left.\left.\left.{ }_{\phi \Delta} \mathrm{DP} \ldots \quad\left[{ }_{\theta \Delta} \mathrm{DP} \mathrm{XP}\right]\right]\right]\right]$
b. $\left[{ }_{\phi \Delta} \mathrm{DP} \ldots\right.$.P $\vartheta$ anaphor $\left.\left.\ldots\left[{ }_{\theta \Delta} \mathrm{DP} \ldots \mathrm{V} \ldots{ }_{\phi \Delta} \ldots \quad\left[{ }_{\theta \Delta} \mathrm{DP} \mathrm{XP}\right]\right]\right]\right]$

The last question I am going to mention (briefly) is whether this striking similarity is any bad. One could argue against a collapse of SC- and ECM-syntax in all practical matters relevant to the anti-locality framework. One possible objection is perhaps the well-known extraction asymmetry found in SCs, already noted by Kayne (1984). As (54) shows, only the predicate of a SC may be extracted from:

(54) a. * Who did you consider [[the sister of whe] [a friend of Mary]]?

b. Who did you consider [[the sister of John] [a friend of whe]]? 
Should we now conclude that SC-subjects can't move (overtly) into a matrix object position, because they don't behave much like objects? The natural answer should be "no." After all, the same holds for ECM-constructions:

(55) a. * Who did you expect [the sister of whe] to kiss [a friend of Mary]?

b. Who did you expect [the sister of John] to kiss [a friend of whe]?

One might, of course, object and consider these data evidence against a movement analysis of for ECM-constructions as well, under which the ECM-subject stays (and receives/checks Case) in the embedded clause. But an alternative explanation is available, and it is a more general one as well. Note that the landing site in the matrix clause (e.g. AgrOP) is a specifier position and as such a left branch. Hence both (54a) and (55a) are ruled out by whatever rules out extractions from left branches in general.

\section{Conclusion}

This paper took as its starting point the radical derivational direction formulated by Hornstein (2001a) and investigates relevant predication structures in a specific model, the anti-locality framework (Grohmann 2000a, 2001b). Subject of investigation was the question how small clauses fit into the partitioning into Prolific Domains, and one of the main conclusions is to liken them to ECM-constructions. As such, the subject of an SC moves in the overt syntax into the matrix clause. As an anaphoric subject, it also spells out in the matrix $\phi$-domain as a reflexive, for example, after moving into a matrix $\theta$-position. A non-anaphoric SC-subject, on the other hand, moves straight into the matrix $\phi$-position. The same analysis was argued to hold for ECMsubjects. This derives fairly naturally the Case properties of SC-subjects.

\section{References}

Anagnostopoulou, Elena, Henk van Riemsdijk \& Frans Zwarts, eds. 1997. Materials on Left Dislocation. Amsterdam: John Benjamins.

Aoun, Joseph \& Elabbas Benmamoun. 1998. Minimality, Reconstruction and PF-Movement. Linguistic Inquiry 29, 569-597.

Aoun, Joseph, Lina Choueiri \& Norbert Hornstein. 2001. Bound Pronominals. Linguistic Inquiry 32, 371-403.

Baker, Mark. 1997. Thematic Roles and Grammatical Categories. In Liliane Haegeman, ed. Elements of Grammar: Handbook of Generative Syntax. Dordrecht: Kluwer, 73-137.

Boeckx, Cedric. 2000. Eliminating EPP. Manuscript, University of Connecticut, Storrs.

Bošković, Željko. 1997c. The Syntax of Non-Finite Complementation. An Economy Approach. Cambridge, MA: MIT Press. 
Bošković, Željko. 2001. A-Movement and the EPP. Manuscript, University of Connecticut, Storrs.

Bowers, John S. 1973. Grammatical Relations. Doctoral dissertation, Massachusetts Institute of Technology, Cambridge.

Bowers, John S. 1981. The Theory of Grammatical Relations. Ithaca, NY: Cornell University Press.

Bowers, John S. 1993. The Syntax of Predication. Linguistic Inquiry 24, 591-656.

Bresnan, Joan. 1978. A Realistic Transformational Grammar. In Morris Halle, Joan Bresnan \& George Miller, eds. Linguistic Theory and Psychological Reality. Cambridge, MA: MIT Press, 1-59.

Browning, Marguerite A. 1987. Null Operator Constructions. Doctoral dissertation, Massachusetts Institute of Technology, Cambridge.

Cardinaletti, Anna \& Maria-Teresa Guasti, eds. 1995. Syntax and Semantics 28: Small Clauses. New York: Academic Press.

Castillo, Juan Carlos, John Drury \& Kleanthes K. Grohmann. 1999. Merge Over Move and the Extended Projection Principle. In Sachiko Aoshima, John Drury \& Tuomo Neuvonen, eds. University of Maryland Working Papers in Linguistics 8, 63-103.

Chomsky, Noam. 1955. The Logical Structure of Linguistic Theory. Mimeograph, Harvard University. [Published 1975. New York: Plenum.]

Chomsky, Noam. 1981. Lectures on Government and Binding. Dordrecht: Foris.

Chomsky, Noam. 1982. Some Concepts and Consequences of the Theory of Government and Binding. Cambridge, MA: MIT Press.

Chomsky, Noam. 1986a. Barriers. Cambridge, MA: MIT Press.

Chomsky, Noam. 1991. Some Notes on Economy of Derivation and Representation. In Robert Freidin, ed. Principles and Parameters in Generative Grammar. Cambridge, MA: MIT Press, 417-454.

Chomsky, Noam. 1995. The Minimalist Program. Cambridge, MA: MIT Press.

Chomsky, Noam. 2000. Minimalist Inquiries: The Framework. In Roger Martin, David Michaels \& Juan Uriagereka, eds. Step by Step. Essays on Minimalist Syntax in Honor of Howard Lasnik. Cambridge, MA: MIT Press, 89-155.

Chomsky, Noam \& Howard Lasnik. 1993. The Theory of Principles and Parameters. In Joachim Jacobs, Arnim von Stechow, Wolfgang Sternefeld \& Theo Vennemann, eds. Syntax: Ein internationales Handbuch zeitgenössischer Forschung - An International Handbook of Contemporary Research, Vol. I. Berlin: Mouton de Gruyter, 506-570.

Epstein, Samuel David \& T. Daniel Seely. 1999. SPEC-ifying the GF "Subject;" Eliminating AChains and the EPP within a Derivational Model. Manuscript, University of Michigan, Ann Arbor \& Eastern Michigan University, Ypsilante.

Grohmann, Kleanthes K. 1997. On Left Dislocation. Groninger Arbeiten zur germanistischen Linguistik 40, 1-33

Grohmann, Kleanthes K. 2000a. Prolific Peripheries: A Radical View from the Left. Doctoral dissertation, University of Maryland, College Park.

Grohmann, Kleanthes K. 2000b. Copy Left Dislocation. In Roger Billerey \& Brook Danielle Lillehaugen, eds. Proceedings of the Nineteenth West Coast Conference on Formal Linguistics. Somerville, MA: Cascadilla Press, 139-152.

Grohmann, Kleanthes K. 2000c. A Movement Approach to Contrastive Left Dislocation. Rivista di Grammatica Generativa 25, 3-65. 
Grohmann, Kleanthes K. 2001a "Natural Relations": A note on X'-Structure. ZAS Papers in Linguistics 21, 67-87

Grohmann, Kleanthes K. 2001b. Symmetries in Locality. Manuscript, Johann Wolfgang GoetheUniversität Frankfurt am Main and Zentrum für allgemeine Sprachwissenschaft, Typologie und Universalienforschung, Berlin.

Grohmann, Kleanthes K., John Drury \& Juan Carlos Castillo. 2000. No More EPP. In Roger Billerey \& Brook Lillehaugen, eds. Proceedings of the Nineteenth West Coast Conference on Formal Linguistics. Somerville, MA: Cascadilla Press, 153-166.

Grohmann, Kleanthes K. \& Liliane Haegeman. In progress. Resuming Reflexives. Manuscript, Johann Wolfgang Goethe-Universität Frankfurt am Main \& Université Charles de Gaulle Lille III.

Guéron, Jacqueline \& Teun Hoekstra. 1995. The Temporal Interpretation of Predication. In Cardinaletti \& Guasti (1995), 77-107.

Hale, Kenneth \& Samuel Jay Keyser. 1993. On Argument Structure and the Lexical Expression of Grammatical Relations. In Kenneth Hale \& Samuel Jay Keyser, eds. The View from Building 20. Essays in Honor of Sylvain Bromberger. Cambridge, MA: MIT Press, 53-110.

Heycock, Caroline. 1994. Layers of Predication. New York: Garland.

Hornstein, Norbert. 1998. Movement and Chains. Syntax 1, 99-127.

Hornstein, Norbert. 1999. Movement and Control. Linguistic Inquiry 30, 69-96.

Hornstein, Norbert. 2001a. Move! A Minimalist Theory of Construal. Oxford: Blackwell.

Hornstein 2001b. On Control. Manuscript, University of Maryland, College Park.

Jespersen, Otto. 1924. The Philosophy of Grammar. New York: Henry Holt and Co.

Kayne, Richard S, 1984. Connectedness and Binary Branching. Dordrecht: Foris.

Koizumi, Masatoshi. 1993. Object Agreement Phrases and the Split VP Hypothesis. In Jonathan David Bobaljik \& Colin Phillips, eds. Papers on Case and Agreement I. MIT Working Papers in Linguistics 18, 99-148.

Koizumi, Masatoshi. 1995. Phrase Structure in Minimalist Syntax. Doctoral dissertation, Massachusetts Institute of Technology, Cambridge.

Lasnik, Howard. 1995a. Last Resort. In Shosuke Haraguchi \& Michio Funaki, eds. Minimalism and Linguistic Theory. Tokyo: Hitzui Syobo, 1-32. [Reprinted in Lasnik (1999), 120-150.]

Lasnik, Howard. 1995b. A Note on Pseudogapping. In Rob Pensalfini \& Hiroyuki Ura, eds. Papers on Minimalist Syntax. MIT Working Papers in Linguistics 27, 143-163. [Reprinted in Lasnik (1999), 151-174.]

Lasnik, Howard. 1999. Minimalist Analysis. Oxford: Blackwell.

Lasnik, Howard \& Mamoru Saito. 1993. On the Subject of Infinitives. In Lise K. Dobrin, Lynn Nichols \& Rosa M. Rodriguez, eds. Papers from the 27th Regional Meeting of the Chicago Linguistic Society 1991. Part 1: The General Session. University of Chicago: Chicago Linguistics Society, 324-343. [Reprinted in Lasnik (1999), 7-24.]

Lees, Robert \& Edward Klima. 1963. Rules for English Pronominalization. Language 39, 17-28.

Lidz, Jeffrey \& William J. Idsardi. 1997. Chains and Phono-Logical Form. In Alexis Dimitriadis, Hikyoung Lee, Christine Moisset \& Alexander Williams, eds. Proceedings of the 22nd Annual Penn Linguistics Colloquium. University of Pennsylvania Working Papers in Linguistics 5.1, 109-125.

Manzini, Rita M. 1983. Restructuring and Reanalysis. Doctoral dissertation, Massachusetts Institute of Technology, Cambridge. 
Manzini, M. Rita \& Anna Roussou. 2000. A Minimalist Approach to A-Movement and Control. Lingua 110, 409-447.

Martin, Roger. 1996. A Minimalist Theory of PRO and Control. Doctoral dissertation, University of Connecticut, Storrs.

Moro, Andrea. 1988. Per una teoria unificata delle frasi copulari. Rivista di Grammatica Generativa 13, 81-110.

Moro, Andrea. 1997. The Raising of Predicates. Cambridge: Cambridge University Press.

Moro, Andrea. 2000. Dynamic Antisymmetry. Cambridge, MA: MIT Press.

Nunes, Jairo. 1995. The Copy Theory of Movement and Linearization of Chains in Minimalist Program. Doctoral dissertation, University of Maryland, College Park.

Nunes, Jairo. 1999. Linearization of Chains and Phonetic Realization of Chain Links. In Epstein \& N. Hornstein (1999), 217-249.

O’Neil, John. 1995 Out of Control. In Jill N. Beckman, ed. Proceedings of NELS 25. Amherst, MA: GLSA, 361-71.

Pereltsvaig, Asya. 2001. On the Nature of Intra-Clausal Relations: A Study of Copular Sentences in Russian and Italian. Doctoral dissertation, McGill University, Montreal.

Platzack, Christer. 2001. Multiple Interfaces. In Urpo Nikanne \& Emile van der Zee, eds. Cognitive Interfaces. Constraints on Linking Cognitive Information. Oxford: Oxford University Press, 21-53.

Poletto, Cecilia. 2000. The Higher Functional Field. Oxford: Oxford University Press.

Pollock, Jean-Yves. 1989. Verb Movement, UG and the Structure of IP. Linguistic Inquiry 20, 365-424.

Rafel, Joan. 2000. Complex Small Clauses. Doctoral dissertation, Universitat Autònoma de Barcelona.

van Riemsdijk, Henk. 1997. Left Dislocation. In Anagnostopoulou, van Riemsdijk \& Zwarts (1997), 1-10.

Rizzi, Luigi. 1990. Relativized Minimality. Cambridge, MA: MIT Press.

Rizzi, Luigi. 1997. The Fine Structure of the Left Periphery. In Liliane Haegeman, ed. Elements of Grammar: Handbook of Generative Syntax. Dordrecht: Kluwer, 281-337.

Rothstein, Susan. 1995. Small Clauses and Copular Constructions. In Cardinaletti \& Guasti, eds., 27-48.

Schein, Barry. 1995. Small Clauses and Predication. In Anna Cardinaletti \& Maria-Teresa Guasti (1995), 49-76.

Stowell, Tim. 1981. Origins of Phrase Structure. Doctoral dissertation, Massachusetts Institute of Technology, Cambridge.

Stowell, Tim. 1983. Subjects Across Categories. The Linguistic Review 2, 285-312.

Svenonius, Peter. 1994. Dependent Nexus: Subordinate Predication Structures in English and the Scandinavian Languages. Doctoral dissertation, University of California, Santa Cruz.

Uriagereka, Juan. 1999. Multiple Spell Out. In Samuel David Epstein \& Norbert Hornstein, eds. Working Minimalism. Cambridge, MA: MIT Press, 251-282.

Williams, Edwin. 1983. Against Small Clauses. Linguistic Inquiry 14, 287-308.

Williams, Edwin. 1994. Thematic Structure in Syntax. Cambridge, MA: MIT Press.

Zwart, C. Jan-Wouter. 1996. "Shortest Move" versus "Fewest Steps". In Werner Abraham, Samuel David Epstein, Höskuldur Thráinsson \& C. Jan-Wouter Zwart eds. Minimalist Ideas. Amsterdam: John Benjamins, 305-327. 